\title{
Redes Sociais: O tumblr e suas práticas escolares.
}

Danielly Ferreira Oliveira de Paula - Graduanda em Sistemas de Informação da Universidade Estadual de Pernambuco - UPE - dfo.paula@gmail.com

Marjony Barros Camelo - Professor Mestre do Curso de Sistemas de Informação da Universidade Estadual de Pernambuco - UPE - marjonycamelo@uol.com.br

\section{Resumo}

Este artigo objetiva analisar a aplicação do tumblr, como uma ferramenta de ensino com o intuito de quebrar o tradicionalismo das salas de aula e deixar o processo de ensino-aprendizagem mais atrativo. A pesquisa foi realizada em uma turma do ensino médio de uma escola de rede pública localizada em Olinda-PE. Para a metodologia realizou-se uma pesquisa exploratória de natureza quantitativa, onde foram analisados questionários aplicados aos alunos, o primeiro com o intuito de identificar qual a melhor prática para inserir a rede social tumblr em um ambiente escolar, e o segundo para medir se a aplicação foi eficaz. Como resultado, esta pesquisa caracteriza a turma escolhida, apresenta quais atividades foram realizadas e o resultado da análise feita após a coleta de dados, diante do uso de uma pedagogia diferenciada.

Palavras-chave: Redes sociais, tumblr, modelo de aula, educação.

\section{Social Networks: The tumblr and their school practices.}

\begin{abstract}
This article aims at reviewing the implementation of tumblr as a teaching tool in order to break the traditionalism of the classroom and leave the teaching-learning process more attractive. The survey was conducted in a class of high school in a public school located in Olinda, Pernambuco. For this method we carried out a quantitative exploratory research, which analyzed questionnaires given to students, the first in order to identify the best practice to enter the social network tumblr in a school environment, and the second to measure the application was effective. As a result, this paper characterizes the class chosen, shows what activities were performed and the results of analysis after the collection of data on the use of a differentiated pedagogy.
\end{abstract}

.Keywords: Social networks, tumblr, class model, education.

\section{Introdução}

O conceito de aula está mudando, hoje em dia estão sendo utilizadas novas maneiras de transmitir informações e gerar conhecimento (Moran, 2001). Um exemplo é a internet, que atua como uma nova mídia para educação, através da web veio uma 
forma fácil e imediata de disseminação de conhecimento, além de ser muito utilizada pelos jovens por ser dinâmica e atrativa Segundo Garcia (s.d), no ramo da educação a internet pode ser considerada a mais abrangente e completa ferramenta de aprendizado do mundo.

O que mais tem se expandido na web são as redes de relacionamentos virtuais, estas são um tipo de mídia social cujo número de usuários tem crescido bastante, pois é através dela que os usuários se reconhecem, comunicam, interagem e informam (Araújo, 2010). Também conhecidas como redes sociais, estas mídias possibilitam um novo formato educacional, pois estabelecem um relacionamento diferenciado entre professor e aluno. Para Garcia (s.d), os professores devem entrar nesse novo processo de ensino e aprendizagem, onde os meios eletrônicos de comunicação são a base para o compartilhamento de ideias.

O conhecimento adquirido em sala de aula não deve ter fim na mesma, ele precisa ter continuidade fora dela, e as redes sociais são um meio para que isso ocorra, pois os alunos e o professor podem conversar e interagir uns com os outros e trocar informações sem a necessidade de um mesmo espaço físico. A Internet está cada vez mais presente no sistema educacional e nas escolas, esse tipo de redes pode ser utilizada no processo pedagógico para romper as paredes da escola (Garcia, s.d).

Uma análise simples torna possível perceber o desinteresse dos alunos no espaço escolar (salas de aula), devido ao padrão de ensino e a densidade dos conteúdos curriculares das disciplinas (Costa, 2010). Logo, usar as redes sociais como ferramenta para a educação viria como uma forma de quebrar o tradicionalismo e apresentar um novo cenário educacional que seja dinâmico e interessante para os envolvidos.

Diante deste panorama esta pesquisa tem como objetivo analisar o uso das redes sociais, mais especificamente o tumblr, como uma ferramenta de apoio no processo ensino-aprendizagem, em uma turma de terceiro ano do ensino médio, na escola pública Compositor Antônio Maria em Olinda-PE.

\section{Conceitos}

\subsection{Redes Sociais}

Uma rede social é um conjunto de indivíduos ou grupos que possuem relacionamentos de algum tipo entre si (Newman, 2001). Segundo Aguiar (2007), o conceito de "redes" envolve relações de comunicação e/ou intercâmbio de informação e trocas culturais ou interculturais que remetem a inter-relações, associações encadeadas, interações, vínculos não hierarquizados. Para entender o comportamento social dessas relações é preciso uma análise dessas redes.

Redes Sociais podem ser representadas de diversas maneiras, uma delas é o método de grafos. De acordo com Menezes et al. (2008) para estudar as redes sociais, é preciso entender uma ferramenta matemática chamada de grafos. A teoria dos grafos foi criada pelo matemático Euler, um grafo é uma representação gráfica de um conjunto de nós, que são conectados por arestas que formam uma rede. Assim, os nós dos grafos são os usuários da rede (autor), e as arestas são os relacionamentos entre eles (colaboração). Na Figura 1 podemos observar esse tipo rede: 


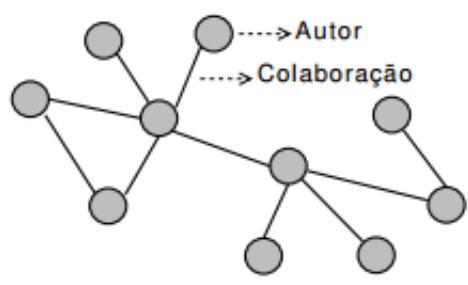

Figura 1 - Rede de Colaboração.

Fonte: Menezes et al. (2008).

De acordo com Boyd e Ellison (2007), as redes sociais devem permitir a construção de um perfil (semi) público do usuário, ter acesso a uma lista de outros usuários que seja possível compartilharem uma conexão, e possibilitar a visualização dessas conexões criadas. Segundo Mislove et al. (2007) alguns componentes são essenciais nas redes sociais: usuários cadastrados, possibilidade de criar links entre usuários e a possibilidade de segmentar os links em grupos para que seja possível unir os usuários que possuem o mesmo tipo de interesse.

São diversos os interesses dos usuários nas redes sociais, que vão desde compartilhar informações, criar conteúdo próprio, acompanhar/ler noticias, entre outros. Estes métodos de manuseio das redes sociais podem ser utilizados por empresas/organizações para benefício próprio. Segundo Aguiar (2006), as redes sociais também podem ser usadas por grupos com poder de liderança, que articulam pessoas em torno de interesses, necessidades e/ou objetivos (estratégicos e táticos) comuns, estes participantes representam (ou atuam em nome de) associações, movimentos, comunidades, empresas, etc., ou seja, a atuação deles é apenas institucionalmente.

\subsection{Redes Sociais utilizadas na pesquisa}

A rede social escolhida para esta pesquisa foi apenas uma, o tumblr. O motivo da escolha foi além de ser bastante popular e difundido no Brasil, possui características que podem ser utilizadas pedagogicamente para a educação.

\subsubsection{Tumblr}

De acordo com a definição de Boyd e Ellison (2007), o tumblr é uma rede social. Foi fundado em 2007, é uma plataforma de blogging que permite aos usuários criarem páginas pessoais, que podem ser publicados: texto, imagem, citação, links, chat, áudio e vídeo.

No seu site, na sessão About (Sobre), o Tumblr define-se da seguinte forma:

\footnotetext{
O Tumblr permite que você compartilhe qualquer coisa, sem esforço. Poste textos, fotos, citações, links, músicas e vídeos a partir do seu browser, seu telefone, seu desktop, e-mail ou de onde quiser. Você pode customizar tudo, das cores ao html do seu tema.
}

O tumblr possui as seguintes características: o usuário cria sua página pessoal e pode seguir as atualizações de outras páginas e ser seguido também, além de poder dar "reblog", ou seja, replicar a atualização de outro usuário. Como ele não se limita a 140

\footnotetext{
${ }^{1}$ Retirado do site: http://www.tumblr.com Acessado em 25/03/2012
} 
caracteres, é bastante usado como um blog convencional, o usuário tem a possibilidade de editar o html para modificar a sua interface, além de existir uma variedade de plugins e widgets.

\subsection{Inovação Tecnológica na educação}

Diversos pensadores têm se preocupado com uma escola alienante e estática (Solé e Coll, 2004). Portanto uma nova abordagem deve ser experimentada com o intuito de promover uma melhor dinamicidade nas salas de aula. Para Capobianco (2010), Tecnologias de Informação e Comunicação (TIC) possuem recursos que podem favorecer e enriquecer o processo da educação, além de que a adoção desses recursos na aprendizagem complementa a educação formal. Segundo Bittencourt (2009) o uso dos computadores provocou uma mudança cultural que gera alunos com novas habilidades e diferentes capacidades de entender o mundo.

Partindo da concepção de Gardner (2000, p. 16):

O propósito da escola deveria ser o de desenvolver as inteligências e ajudar as pessoas a atingirem objetivos de ocupação e passatempo adequados ao seu espectro particular de inteligências. As pessoas que são ajudadas a fazer isso (...) se sentem mais engajadas e competentes, e, portanto mais inclinadas a servirem a sociedade.

Diante desses fatores, é importante perceber que a inserção de novas tecnologias no âmbito educacional não se limita apenas a uma reformulação na rotina de sala de aula, mas também a postura do professor deve ser uma nova. De acordo com Lévy (1999), o professor perde sua principal função de transmitir a notação de exercícios e passa a guiar os alunos para uma busca dessas informações, com isso, o professor tornase um animador do aprendizado. A relação professor-aluno também será diferente, uma vez que o professor servirá apenas como auxiliador para que o aluno construa seu próprio caminho de conhecimento.

\subsection{Estratégia Educacional}

De acordo com Petrucci e Batiston (2006, p. 263):

[...] a palavra 'estratégia' possui estreita ligação com o ensino. Ensinar requer arte por parte do docente, que precisa envolver o aluno e fazer com ele se encante com o saber. O professor precisa promover a curiosidade, a segurança e a criatividade para que o principal objetivo educacional, a aprendizagem do aluno, seja alcançado.

Logo, estratégia educacional são os métodos que o professor utiliza para ministrar suas aulas e abordar as atividades para os alunos.

Segundo Luckesi (1994) é necessário escolher qual proposta pedagógica e metodológica o docente irá utilizar, pois a escolha do procedimento gera consequência na prática das atividades.

A proposta metodológica aplicada, como estratégia de ensino, nessa pesquisa segue o modelo recomendado por Anastasiou e Alves (2004), porém não foram utilizados todos os métodos. Segue uma tabela abaixo com as atividades praticadas durante a pesquisa de campo, e com suas respectivas definições segundo Anastasiou e Alves (2004): 
Quadro 1 - Estratégias de ensino empregadas na pesquisa e suas definições.

\begin{tabular}{|l|l|}
\hline \multicolumn{1}{|c|}{ Estratégia de ensino } & \multicolumn{1}{|c|}{ Definição } \\
\hline $\begin{array}{l}\text { Aula expositiva } \\
\text { dialogada }\end{array}$ & $\begin{array}{l}\text { "O professor leva os estudantes a questionarem, } \\
\text { interpretarem e discutirem o objeto de estudo, a partir do } \\
\text { reconhecimento e do confronto com a realidade." } \\
\text { (ANASTASIOU e ALVES, 2004, p. 79). }\end{array}$ \\
\hline Estudo de texto & $\begin{array}{l}\text { "É a exploração de ideias de um autor a partir do estudo } \\
\text { crítico de um texto e/ou a busca de informações e } \\
\text { exploração de ideias dos autores estudados." } \\
\text { (ANASTASIOU e ALVES, 2004, p. 80). }\end{array}$ \\
\hline $\begin{array}{l}\text { Lista de discussão por } \\
\text { meios informatizados }\end{array}$ & $\begin{array}{l}\text { "[..] debater, à distância, um tema sobre o qual sejam } \\
\text { especialistas ou tenham realizado um estudo prévio, ou } \\
\text { queiram aprofundá-lo por meio eletrônico." } \\
\text { (ANASTASIOU e ALVES, 2004, p. 85). }\end{array}$ \\
\hline Solução de problemas & $\begin{array}{l}\text { "É o enfrentamento de uma situação nova, exigindo } \\
\text { pensamento reflexivo, crítico e criativo a partir dos dados } \\
\text { expressos na descrição do problema" (ANASTASIOU e } \\
\text { ALVES, 2004, p. 86). } \\
\text { "É um estudo direto do contexto natural e social no qual o } \\
\text { estudante se insere, visando a uma determinada } \\
\text { problemática de forma interdisciplinar." (ANASTASIOU; } \\
\text { ALVES, 2004, p. 97). }\end{array}$ \\
\hline Estudo do meio & $\begin{array}{l}\text { "Concepção de conhecimento e ciência em que a dúvida e a } \\
\text { crítica sejam elementos fundamentais; assumir o estudo } \\
\text { como situação construtiva e significativa." (ANASTASIOU } \\
\text { e ALVES, 2004, p. 98). }\end{array}$ \\
\hline Ensino com pesquisa \\
\hline
\end{tabular}

Fonte: elaborado com base em ANASTASIOU e ALVES (2004, p. 79).

\section{Materiais e Métodos}

Todo projeto deve definir a modalidade de pesquisa e determinar os procedimentos de coleta e análise de dados (Gil, 2002). Para esta pesquisa serão consideradas opiniões e informações para posteriormente analisá-las, para isso serão utilizados recursos e técnicas estatísticas, caracterizando assim uma pesquisa quantitativa (Silva \& Menezes, 2001). De acordo com os objetivos dessa pesquisa, ela é do tipo exploratória. Segundo Gil (2002) pode-se dizer que estas pesquisas têm como objetivo principal o aprimoramento de ideias ou a descoberta de intuições. A pesquisa foi realizada no $3^{\circ} \mathrm{A}$ do ensino médio na escola Compositor Antônio Maria.

A metodologia adotada está estruturada em quatro passos fundamentais, mostrados a seguir:

Aplicação do primeiro questionário: foi escolhido o questionário como instrumento de coleta de dados, pois de acordo com Cervo et al. (2007) o questionário possibilita 
medir com mais exatidão o que se deseja. $O$ questionário foi sequencialmente organizado baseado na análise de um instrumento de coleta de dados proposto por Bastos \& Silva (2005).

Foram aplicados, pessoalmente, 18 questionários (quantitativo de alunos na turma), compostos somente por questões fechadas de múltipla-escolha, com o objetivo de caracterizar o perfil dos alunos e analisar o perfil de uso das redes sociais, com o intuito de identificar métodos possíveis para inserir as redes sociais no processo pedagógico.

Realização das atividades: As atividades foram baseadas em Anastasiou e Alves (2004), e foi realizada com a disciplina de português. A turma foi dividida em quatro grupos e cada grupo criou uma conta no tumblr. A professora também criou. As atividades foram divididas em três experimentos. Inicialmente foi realizado o primeiro experimento (elaborar um texto dissertativo) que consistiu em não ter aula em sala de aula, o conteúdo foi passado usando somente as Redes Sociais. O material foi disponibilizado no tumblr da professora, no qual os alunos tiveram acesso à leitura e desenvolveram a atividade que lá estava proposta. A resposta de cada grupo foi publicada no seu respectivo tumblr. No experimento 2, primeiramente foi ministrada uma aula em sala de aula sobre o novo conteúdo, e em outro momento os alunos foram direcionados ao laboratório apenas para realizar a atividade (escrever uma resenha crítica sobre a música "Cérebro eletrônico" de Gilberto Gil) que estava publicada no tumblr da professora. Após a atividade feita, a resposta de cada grupo foi publicada em seu respectivo tumblr. No experimento 3 houve aula e atividade (escrever uma carta argumentativa) em sala de aula a respeito de um novo conteúdo, em outro momento foi proposta a mesma atividade, porém com um direcionamento diferente, para ser realizada no laboratório de informática. Novamente a proposta da atividade foi publicada no tumblr da professora, e os alunos publicaram as respostas no tumblr do seu grupo. Em cada experimento houve estudo de textos diferentes e debate entre os integrantes de cada grupo para a realização da atividade

Aplicação do segundo questionário: O segundo questionário foi elaborado pelo autor e aplicado após a realização de todas as atividades, com a intenção de analisar se o uso das Redes Sociais como uma ferramenta de ensino foi eficaz.

Análise dos dados: Os dados dos questionários foram tabulados e analisados, e os resultados serão descritos a seguir.

\section{Análise dos Resultados}

Dos 18 questionários aplicados aos alunos do $3^{\circ} \mathrm{A}$, todos foram respondidos. $\mathrm{A}$ análise dos resultados do primeiro questionário ajudou a caracterizar o $3^{\circ} \mathrm{A}$ e apontou formas de como inserir as rede sociais como uma ferramenta de ensino de modo que os alunos não sintam dificuldade e consigam absorver o conteúdo da disciplina de forma mais dinâmica. Na Tabela 1 a seguir contém o questionário completo com todas as respostas e suas respectivas taxas de porcentagem.

Tabela 1 - Primeiro questionário.

\begin{tabular}{lll}
\hline Perguntas & & \multicolumn{1}{c}{ Respostas } \\
\hline Gênero & $83,3 \%$ & $16,67 \%$ Masculino \\
& Feminino & \\
\hline
\end{tabular}




\begin{tabular}{|c|c|c|c|c|c|}
\hline Tempo de & $0 \%$ & $11,1 \%$ & \multicolumn{3}{|c|}{$88,9 \%$ Mais de 4 anos } \\
\hline Frequência & $\begin{array}{l}22,2 \% \text { - } \\
\text { uma a três } \\
\text { vezes por } \\
\text { semana }\end{array}$ & $\begin{array}{l}38,8 \% \\
\text { Diariamente }\end{array}$ & $\begin{array}{l}16,6 \% \\
\text { Raramente }\end{array}$ & $\begin{array}{l}22,2 \% \text { Conectado } \\
\text { permanentemente }\end{array}$ & $\begin{array}{l}0 \% \\
\text { Não } \\
\text { acesso }\end{array}$ \\
\hline $\begin{array}{l}\text { Local de } \\
\text { Acesso }\end{array}$ & $\begin{array}{l}50 \% \\
\text { Sua Casa }\end{array}$ & $\begin{array}{l}33,3 \% \text { Casa } \\
\text { de um } \\
\text { amigo (a) } \\
\text { ou parente }\end{array}$ & $\begin{array}{l}11,1 \% \text { Lan } \\
\text { House }\end{array}$ & $\begin{array}{l}\text { 0\% Laboratório da } \\
\text { escola }\end{array}$ & $\begin{array}{l}5,5 \% \\
\text { Outro }\end{array}$ \\
\hline $\begin{array}{l}\text { Redes } \\
\text { Sociais } \\
\text { utilizadas }\end{array}$ & $\begin{array}{l}100 \% \\
\text { Facebook } \\
5,5 \% \\
\text { Linkedin }\end{array}$ & $\begin{array}{l}\text { 100\% Orkut } \\
\text { 0\% Flickr }\end{array}$ & $\begin{array}{l}27,7 \% \\
\text { Myspace } \\
\text { 0\% Não uso. }\end{array}$ & $22,2 \%$ Tumblr & $\begin{array}{l}33,3 \% \\
\text { Twitter }\end{array}$ \\
\hline $\begin{array}{l}\text { Finalidade } \\
\text { no uso }\end{array}$ & $\begin{array}{l}5,5 \% \text { Crio } \\
\text { conteúdo } \\
\text { próprio }\end{array}$ & $\begin{array}{l}88,8 \% \\
\text { Comparti- } \\
\text { lho } \\
\text { informações }\end{array}$ & $\begin{array}{l}5,5 \% \\
\text { Acompanho/ } \\
\text { Leio }\end{array}$ & $\begin{array}{l}0 \% \text { Não uso/Não } \\
\text { conheço }\end{array}$ & $\begin{array}{l}0 \% \text { Não } \\
\text { tenho } \\
\text { interes- } \\
\text { se }\end{array}$ \\
\hline $\begin{array}{l}\text { Usa para } \\
\text { estudo? }\end{array}$ & $\begin{array}{l}38,8 \% \\
\text { Sim }\end{array}$ & $\begin{array}{l}22,2 \% \text { Não, } \\
\text { mas tenho } \\
\text { interesse. }\end{array}$ & 38,8\% Não. & & \\
\hline $\begin{array}{l}\text { Dificulda- } \\
\text { des no uso }\end{array}$ & $\begin{array}{l}33,3 \% \\
\text { Falta de } \\
\text { tempo }\end{array}$ & $\begin{array}{l}38,8 \% \\
\text { Ausência de } \\
\text { internet em } \\
\text { casa }\end{array}$ & $\begin{array}{l}38,8 \% \text { Acesso a } \\
\text { internet de } \\
\text { baixa } \\
\text { velocidade }\end{array}$ & $\begin{array}{l}5,5 \% \\
\text { Complexidade } \\
\text { no seu uso }\end{array}$ & $\begin{array}{l}22,2 \% \\
\text { Outro } \\
\text { motivo }\end{array}$ \\
\hline $\begin{array}{l}\text { Mantém } \\
\text { contato } \\
\text { com } \\
\text { colegas de } \\
\text { classe nas } \\
\text { redes } \\
\text { sociais? }\end{array}$ & $\begin{array}{l}100 \% \\
\text { Sim. }\end{array}$ & 0\% Não & & & \\
\hline
\end{tabular}

Portanto ao elaborar atividades educativas nas redes sociais, deve-se observar que: todos os alunos estão familiarizados com as redes sociais, nem todos possuem internet em casa, logo, os exercícios devem ser feitos na escola, todos eles mantém contato com os colegas de classe virtualmente e compartilham informações entre si, logo, o conhecimento poderá ser repassado sem a necessidade de um mesmo espaço físico.

O segundo questionário teve como objetivo verificar se o uso do tumblr como apoio durante o processo e ensino foi eficaz. Os resultados considerados mais significativos são comentados a seguir. Na parte de experimentos, teve o objetivo de medir o nível de dificuldade que cada aluno sentiu ao realizar os experimentos, A primeira pergunta foi sobre o primeiro experimento, onde $11 \%$ tiveram "Muita" dificuldade, 28\% "Moderada", 39\% "Pouca", 22\% "Nenhuma" e 11\% "Não fiz". Logo, poucos alunos tiveram muita dificuldade em entender o assunto abordado usando apenas as redes sociais. A próxima pergunta foi sobre o experimento 2, onde $17 \%$ 
marcaram "Muita" dificuldade, 22\% "Moderada", 28\% "Pouca", 11\% "Nenhuma" e $22 \%$ "Não fiz". Neste caso o resultado ficou bem distribuído, porém novamente poucos alunos tiveram dificuldade em realizar a atividade apenas no laboratório. A última pergunta desta parte correspondeu ao terceiro experimento, "Você preferiu fazer a carta argumentativa em sala de aula (no próprio caderno) ou no laboratório de informática (no tumblr do grupo)?", onde 33\% marcaram "Em sala de aula" e 67\% no "Laboratório da escola" e todos fizeram. Portanto, mais da metade dos alunos tiveram mais facilidade em realizar a atividade por meio tecnológico. A próxima pergunta correspondeu à sessão sobre a importância das Redes Sociais no processo pedagógico, a primeira pergunta busca identificar a opinião dos alunos em relação ao novo modelo aula, se com a quebra do tradicionalismo, as aulas ficaram mais divertidas e interessantes. Os alunos responderam 67\% que "Sim", 33\% marcaram "Um pouco" e nenhum deles marcou "Não". Logo, de acordo com os alunos usar tecnologia nas aulas realmente as torna mais dinâmicas. A próxima pergunta foi para medir se os alunos gostariam de uma continuidade da pesquisa envolvendo outras disciplinas, $83 \%$ afirmaram que "Sim" e $17 \%$ afirmaram que "Não". A última pergunta desta categoria buscou identificar o nível de satisfação dos alunos em relação à experiência proporcionada pela pesquisa, $6 \%$ marcaram "indiferentes", $11 \%$ "Pouco satisfeitos" e 83\% "Satisfeitos". Logo, a maioria dos alunos se sentiu satisfeitos com o modelo de aula proposto. A próxima pergunta foi para medir se a tecnologia ajudou a entender os assuntos da disciplina, 56\% marcaram que "Sempre", 28\% "Frequentemente", 11\% "Às vezes" e 5\% "Nunca". Apesar de o resultado estar bastante distribuído, apenas uma pessoa afirmou que o uso da tecnologia não ajudou na compreensão dos assuntos da disciplina. Todos os outros alunos apontam que, mesmo que sempre ou poucas vezes, a tecnologia ajuda. Portanto as redes sociais não devem ser ignoradas em relação a sua capacidade de enriquecer o processo educacional.

Com o término das atividades a professora deu o seguinte depoimento "Ter participado deste projeto foi bastante enriquecedor e desafiante para mim, pois sempre tive dificuldades nessa área de informática. Porém a união da disciplina de português com as redes sociais foi bastante gratificante, e produtiva, pois houve uma maior interação, envolvimento e interesse por parte dos alunos".

\section{Conclusões}

Conforme apresentado neste trabalho a tecnologia tem o poder de contribuir na educação escolar, pois além de ser uma forma fácil de disseminação de conhecimento é muito utilizada pelos jovens. Esta pesquisa propôs uma forma diferenciada de ministrar aulas usando as redes sociais, mais especificamente o tumblr.

Portanto utilizar o tumblr como um apoio ao processo de ensino-aprendizagem é uma alternativa, que como mostrada no decorrer do trabalho, apresenta contribuições e avanços no cenário educacional. Além de oferecer oportunidades de uma maior interação professor-aluno. Uma das razões deste modelo ter dado certo foi o fato de que as redes sociais fazem parte do cotidiano dos alunos, logo como os alunos já estão familiarizados com o seu uso, não houve muita dificuldade. Uma vez que é incrementado algo do cotidiano com aprendizado, logo, as ações de busca do conhecimento tornam-se algo também do cotidiano. Dessa forma, o professor é o elemento necessário para que oriente os alunos e os faça se sentir motivados a explorar os recursos que as redes proporcionam. 


\section{Referências Bibliográficas}

AGUIAR, Sônia. Redes sociais e tecnologias digitais de informação e comunicação. Nupef, 2006.

ANASTASIOU, Léa das Graças Camargos; ALVES, Leonir Pessate. Estratégias de ensinagem. In: ANASTASIOU, Léa das Graças Camargos; ALVES, Leonir Pessate. (Orgs.). Processos de ensinagem na universidade. Pressupostos para as estratégias de trabalho em aula. 3. ed. Joinville: Univille, 2004. p. 67-100.

ARAÚJO, Verônica Danielle de Lima. O impacto das redes sociais no processo de ensino e aprendizagem. $3^{\circ}$ Simpósio Hipertexto e Tecnologias na educação, 2010.

BASTOS, Bartira; SILVA Lídia. Comunidade científica nas malhas da rede: que rotinas cognitivas e sociais estão sendo alteradas pelos usos da internet no quotidiano da pesquisa? Dimensões para a definição de um padrão de averiguação. Universidade de Aveiro/Portugal, 2005.

BITTENCOURT, Circe Maria Fernandes. Ensino de História: fundamentos e métodos. 3. ed. São Paulo: Cortez, 2009.

BOYD, D.B. e ELLISON, N.B. "Social Network Sites: Definition, History, and Scholarship". In: Journal of Computer-Mediated Communication, 2007.

CAPOBIANCO, L. Comunicação e Literacia Digital na Internet - Estudo etnográfico e análise exploratória de dados do Programa de Inclusão Digital AcessaSP PONLINE. Dissertação (Mestrado em Ciências da Comunicação). Escola de Comunicação e Artes, Universidade de São Paulo, 2010.

CERVO. A. L., BERVIAN, P. A., SILVA, R. Metodologia científica. 6. ed. São Paulo: Pearson Prentice Hall, 2007.

COSTA, Marcella Albaine Farias. As redes sociais como possibilidade: uma nova forma de ensinar, aprender e divulgar o conhecimento histórico. $3^{\text {o }}$ Simpósio Hipertexto e Tecnologias na educação, 2010.

GARCIA, Paulo Sérgio. A Internet como nova mídia na educação. USP. Retirado do link: http://www.grupodemidiasc.com/upload/content/0_03.pdf Acessado em: 16-032012

GARDNER, Howard. Inteligências múltiplas: a teoria na prática. Porto Alegre: Artes Médicas, 2000. (Tradução de Maria Adriana Veríssimo Veronese).

GIL, Antônio Carlos. Como elaborar projetos de pesquisa. 4. ed. - São Paulo: Atlas, 2002.

LÉVY, Pierre. Cibercultura. São Paulo: 34, 1999.

LUCKESI, Cipriano Carlos. Filosofia da educação. São Paulo: Cortez, 1994.

MENEZES, G.V., ZIVIANE N., LAENDER, A.H.F. Um Estudo Comparativo de Redes Sociais em Ciência da Computação. UFMG, 2008. 
MISLOVE, A., MARCONI, M., GUMMANDI, K.P., DRUSCHEL, P. e BHATTCHARJEE, B. "Measurement and Analysis of Online Social Networks". In: Proceedings of the 7th ACM SIGCOMM Conference on Internet Measurement,2007.

MORAN, José Manuel. Novos desafios na educação - a Internet na educação presencial e virtual. Saberes e Linguagens de educação e comunicação, páginas 19-44, 2001.

NEWMAN, M. E. The structure of scientific collaboration networks. Proc. Nat'1. Acad. Sci. of the United States of America, 2001.

PETRUCCI, Valéria Bezzera Cavalcanti; BATISTON, Renato Reis. Estratégias de ensino e avaliação de aprendizagem em contabilidade. In: PELEIAS, Ivam Ricardo. (Org.) Didática do ensino da contabilidade. São Paulo: Saraiva, 2006.

SILVA, Edna Lúcia da, MENEZES, Estera Muszkat Metodologia da pesquisa e elaboração de dissertação $3^{\mathrm{a}}$. ed. rev. atual. - Florianópolis: Laboratório de Ensino a Distância da UFSC, 2001.

SOLÉ, Isabel e COLL César. Os professores e a concepção construtivista. In: COLL, César et al. O Construtivismo na sala de aula. 4 ed. São Paulo: Ática, 1998. pp. 09-29. 